\title{
La eficacia ritual de las performances en y desde los cuerpos
}

\author{
Silvia Citro ${ }^{1}$
}

Universidad de Buenos Aires, Argentina

E-mail: scitro_ar@yahoo.com.ar 
Resumo

Este artigo analisa alguns dos principais processos envolvidos na eficácia ritual de performances festivas. Concentro-me no papel da música e da corporeidade na geração de intensos sentimentos e emoções, e destaco como, através da repetição de um prazer coletivo encarnado, o processo ritual promove um tipo peculiar de docilidade. Meu interesse é discutir a abrangência de uma perspectiva interdisciplinar sobre as experiências corporais nas performances rituais. Em consequência, proponho identificar algumas convergências assinaladas pelas teorias socioantropológicas, abordagens filosóficas e psicanalíticas, e mais recentemente pelas neurociências. Desenvolverei essa perspectiva a partir do caso dos rituais do Evangelho das "igrejas aborígenes" dos Tobas do Chaco argentino, analisando a eficácia da ntonaGak, um estado de "alegria" ou a felicidade obtida através do "canto, dança e louvor", que promove a "saúde ", a "força" e o "poder" entre os performers.

Palavras-chave: Eficácia ritual. Música. Corporeidade. Emoções.
Abstract

This paper examines some of the main processes involved in the ritual efficacy of festive performances. I focus on the role of music and embodiment in the generation of intense sensations and emotions, and I underline how through the collective reiteration of an embodied pleasure, the ritual process promotes a peculiar kind of docility. I am interested in discussing an interdisciplinary perspective about the body experiences in the ritual performances; therefore, I propose to identify some convergences pointed out by socio-anthropological theories, philosophical and psychoanalytical approaches and more recently by the neurosciences. I will develop this perspective starting from the case of the rituals of Evangelio in the "aboriginal churches" of the Toba people from the Argentine Chaco, analyzing the efficacy of the "ntonaGak", a state of bliss or enjoyment reached through "dance, sing and praise", which promotes "health", "strength" and "power" among performers.

Keywords: Ritual efficacy. Music. Embodiment. Emotions. 


\section{Introducción}

"He llegado a la conclusión de que no se puede llegar a tener un punto de vista claro sobre estos hechos [las técnicas corporales], si no se tiene en cuenta una triple consideración, ya sea física o mecánica, como puede serlo una teoría anatómica o fisiológica del andar o que por el contrario sea sociológica o psicológica, lo que hace falta es un triple punto de vista, el del 'hombre total'."

"En el fondo de todo estado místico se dan unas técnicas corporales que no hemos estudiado [...] existen 'medios biológicos' de entrar 'en comunicación con Dios."'

Marcel Mauss (1979, p. 340 y p. 355).

a "eficacia ritual" constituye un tema ya clásico en los estudios
antropológicos, en tanto diferentes teorías se proponen develar los modos en que rituales logran que sus partícipes legitimen las creencias, normas o valores que allí se ponen en juego, promoviendo transformaciones personales, grupales o sociales. Muchos de estos estudios también señalan la importante presencia de las músicas, gestualidades y danzas en las performances rituales de diversas culturas, así como su capacidad para generar emociones intensas entre los partícipes. No obstante, las formas específicas en que las corporalidades, sonoridades y emociones se articulan en las experiencias vividas por los participantes rituales y el modo en que estas experiencias intervienen decididamente en la eficacia del ritual constituyen problemáticas que sólo en las últimas décadas han comenzado a profundizarse (Csordas, 2008; Feld, 1996). Mi intención en este artículo es presentar una argumentación que intenta explicitar algunas de estas experiencias en las performances rituales de carácter festivo, ${ }^{2}$ a partir de una pers- 
pectiva interdisciplinaria que incluye: las etnografías que efectué en distintos contextos rituales y artísticos así como mi propia experiencia como performer en el campo de la música y la danza; la articulación de diferentes teorías socio-antropológicas, filosóficas y psicológicas que he venido desarrollando en trabajos anteriores; y algunas elaboraciones recientes de las neurociencias. A partir de las convergencias pero también de las tensiones entre estas trayectorias etnográficas, teóricas y artísticas, intentaré explicitar los procesos por los cuales la eficacia de ciertas performances se produce, fundamentalmente, en y desde los cuerpos.

Si bien trabajé sobre rituales y performances artísticas de diferentes grupos, me centraré aquí en uno de estos casos, documentado entre 1998 y 2003 en poblaciones rurales de los indígenas tobas de la provincia de Formosa, Argentina: los rituales festivos que se celebran en los "cultos" de sus "iglesias aborígenes" del "Evangelio", en las cuales confluyen creencias y prácticas del chamanismo toba y del evangelismo pentecostal. En especial, me referiré a la eficacia que atribuyen al "gozo/ntonaGak": un estado de "alegría" y emoción intensa que brinda "fortaleza", "salud" y "poder" y que se alcanza, principalmente, a través de la "danza y el canto" colectivos.

Mi explicación apunta a articular tres facetas de la experiencia intersubjetiva vivida por los performers rituales que, según mi hipótesis, serían comunes a los procesos de construcción de la eficacia en diferentes rituales festivos. La primera refiere a la especial capacidad de las músicas y danzas para generar intensidades sensoriales y emotivas que operan como poderosos sentidos icónicos e indexicales entre los performers; la segunda, a la superposición y replicación colectiva de estos lenguajes estéticos en la performance ritual, promoviendo experiencias de fusión perceptiva y mimesis que re-intensifican las sensaciones y emociones vividas y permiten objetivarlas como creencias; y la tercera, destaca cómo estas experiencias, al asociarse al placer y reiterarse a lo largo del tiempo, operan una peculiar "docilidad" en los performers, que permite legitimar las creencias, normas y valores que el ritual promueve.

Si bien estos procesos han sido analizados por diferentes autores, es espacialmente su articulación en la experiencia vivida de los perfor- 
mers así como su capacidad para operar una peculiar "docilidad por el placer" lo que propongo aportar a las teorías de la eficacia ritual. Asimismo, otra de las contribuciones es intentar retomar el legado maussiano del "triple punto de vista" del ser humano "total", en lo que hace al campo que Mauss denominó "técnicas corporales". La conocida frase de Mauss que elegí como epígrafe intenta situarnos frente a una discusión que, como investigadora abocada al campo de la antropología de la corporalidad y la performance, vislumbro hoy fundamental: ¿Podemos seguir estudiando una técnica corporal, sea la del "andar" que señalaba Mauss o la que involucra una danza ritual, como aquí examinaré, ignorando ese "triple punto de vista"? ¿Podemos continuar descartando de nuestras explicaciones sobre el ritual esos "medios biológicos" que, como señalaba el autor, permiten "entrar en comunicación con Dios"?

Durante mucho tiempo las ciencias sociales, psicológicas y biológicas se han atrincherado en sus epistemologías y métodos y han contribuido así a segmentar al ser humano en estas tres dimensiones. Si bien, cada vez más, cada una de estas ciencias reconoce las influencias de los "factores" estudiados por las otras o se promueven los tan difundidos "diálogos interdisciplinarios", a muchos antropólogos sociales, preguntas como las aquí enunciadas aún los interpelan de manera perturbadora. Así, cuando recurrimos y citamos algunos de estos otros saberes, algunos colegas expresan su desconfianza y tienden a deslegitimar estos intentos, por ejemplo, con motes generalizadores que operan casi como anatemas para las ciencias sociales, planteando que implicarían un "biologicismo universalizante" o, por el contrario, un "psicologismo individualizante", imposibles de tolerar en nuestra disciplina. A pesar de estas resistencias, y convencidos de la vigencia que aún posee la interpelación maussiana, con el equipo de investigación de Antropología del Cuerpo y la Performance que coordino en la Universidad de Buenos Aires, hemos venido recorriendo un camino de investigación en cierta forma heterodoxo, pues implicó, en una primera etapa, un diálogo con la fenomenología y el psicoanálisis y, más recientemente, con las elaboraciones de la neurociencias, para intentar enriquecer nuestra comprensión de las experiencias corporales. 
Así, la perspectiva interdisciplinar de este artículo no puede desligarse de estos recorridos de investigación compartidos con los colegas del mencionado equipo.

Quisiera agregar que esta propuesta de "volver" a dialogar con la biología y específicamente con las neurociencias también se basa en que estas disciplinas, en los últimos decenios, han transformado sus paradigmas y, justamente, muchos de esos cambios se han inspirado en conceptos y metáforas provenientes de las ciencias sociales y humanas. Boaventura de Sousa Santos (2009, p. 44) sostiene que nos hallamos ante un nuevo "paradigma emergente", en el cual la "dicotomía entre ciencias naturales y ciencias sociales" dejará de tener sentido, y menciona que es especialmente en el dominio de la biología "donde los modelos explicativos de las ciencias sociales más se enraizaron en las décadas recientes". Respecto de las neurociencias, este cambio de paradigma implica una revalorización de la relación práctica cuerpo-mundo y de la cultura como parte fundamental del entorno que interviene activamente en los procesos de generación del pensamiento. De esta manera, se apartan de los primeros modelos de racionalidad de las ciencias naturales clásicas, y especialmente del primer modelo cartesiano que concebía al cuerpo y la mente como separados, y al ámbito de las emociones como "interferencias" en el razonamiento. Justamente, Antonio Damasio, uno de los neurofisiólogos más renombrados dentro de esta tendencia, tituló a uno de sus libros más difundidos El error de Descartes. Para Damasio (2008, p. 286), el error consiste en la "separación abismal entre el cuerpo y la mente", en

la sugerencia de que el razonamiento, y el juicio moral, y el sufrimiento que proviene del dolor físico o de la conmoción emocional pueden existir separados del cuerpo. Más específicamente: que las operaciones más refinadas de la mente están separadas de la estructura y funcionamiento de un organismo biológico.

En contraste, considera que los denominados fenómenos mentales solo pueden "comprenderse cabalmente en el contexto de interacción de un organismo con su ambiente" físico y social, entendiendo al organismo individual como "el cerebro humano y el resto del cuerpo, 
integrado mediante circuitos reguladores bioquímicos y neuronales mutuamente interactivos" (Damasio, 2008, p. 15). Asimismo, la obra de este autor y también de LeDoux han sido fundamentales para reaproximar cognición y emoción, pues los procesos emocionales son considerados parte integral de la toma de decisiones.

En suma, como sostuvimos en un trabajo anterior (Citro et al., 2011 ), consideramos que estos desarrollos recientes estimulan y habilitan a las ciencias sociales a intentar nuevos diálogos interdisciplinarios con las biologías, aunque desde una mirada atenta a no reincidir en los errores reduccionistas del pasado.

\section{Los rituales tobas del Evangelio}

Antes de desplegar nuestra argumentación sobre la eficacia ritual, reseñaremos la trayectoria histórico-cultural de los tobas y nos aproximaremos a sus rituales, según han sido descriptos por diferentes antropólogos, incluyendo nuestros propios trabajos.

La región chaqueña es una de las áreas indígenas más importantes de la Argentina. Durante el periodo colonial, la subsistencia de estos y otros grupos seminómades de la región se basaba en las prácticas de caza, pesca y recolección, y un elemento que los caracterizó fue su férrea resistencia a la colonización hispánica. Ya en el período republicano, el ejército nacional avanzó sobre sus tierras y, desde finales del siglo XIX, fueron forzados a un proceso de sedentarización e incorporación al mercado de trabajo rural, en ingenios azucareros, explotaciones forestales y otras plantaciones.

Desde mediados del siglo XX, especialmente a partir del gobierno de J. D. Perón, los tobas comienzan un proceso de inclusión ciudadana que les permitió acceder a documentos de identidad y, por tanto, participar de elecciones así como obtener la propiedad legal de algunos territorios. Además, los varones se incorporaron al servicio militar y las nuevas generaciones de niños y niñas, al sistema educativo estatal, convirtiéndose, en su mayoría, en hablantes bilingües toba-español.

La cosmovisión de los tobas y otros pueblos chaqueños históricamente se ha basado en seres no humanos poderosos (jaqa 'a), identificados como "dueños", "padres" o "madres" de diferentes especies 
animales (Cordeu, 1969). Estos seres son centrales en los mitos y en las diversas prácticas de los pi'oGonaq o chamanes tobas; no obstante, como ha destacado Wright (1997), cualquier persona también puede llegar a tener un "encuentro personal" (nachagan) o sueños con alguno de estos jaqa'a. Aquel que acepte el poder de estos seres se transformará en chamán, recibirá sus propios cantos, y aquellos seres poderosos se convertirán en sus espíritus compañeros, o aquellos con "los que habla" (ltaGajaGawa). Así, en una de las performances rituales más difundidas del chamán como es el tratamiento de enfermedades, la cura se efectúa a través del canto con el sonajero de calabaza, del diálogo con su compañero poderoso y con el paciente y de los gestos del soplo y la succión del mal que produce el malestar.

Si bien esta cosmovisión y las prácticas chamánicas continúan vigentes en gran parte de los poblados tobas del Chaco argentino, desde mediados del siglo XX han estado en una relación de "tensión dialéctica" con el evangelismo, es decir, a lo largo de su historia hemos podido constatar relaciones de tensión y conflicto pero también de provisorias síntesis (Citro, 2003 y 2009). La Iglesia Evangélica Unida es la primera iglesia indígena de la Argentina y junto con otras denominaciones constituyó el movimiento denominado "Evangelio", resultado de la interacción entre la religiosidad pentecostal traída por los misioneros blancos y las tradiciones tobas, junto con la asistencia de los menonitas que desde hace más de 60 años asesoran a los "pastores" tobas (Miller, 1979; Wright, 1997). El Evangelio se ha convertido así en la religión dominante en estos grupos y, actualmente, sus celebraciones son los únicos rituales colectivos vigentes. Éstos rituales abarcan, por un lado, los "cultos" regulares que cada iglesia celebra semanalmente con sus fieles, muchos de ellos unidos por lazos de parentesco; y por otro, los rituales especiales que convocan un mayor número de fieles, generalmente miembros de otras iglesias y familias. Entre estos últimos rituales se encuentran los "cumpleaños" y especialmente las "fiestas de quince" de las jóvenes, en donde constatamos elementos característicos de los antiguos rituales de iniciación femenina, y los "casamientos" y los "aniversarios" anuales de las iglesias, en los que se aprecian elementos similares a los encuentros tribales anuales (nie- 
matak), celebrados en la época de maduración de la algarroba (Citro, 2003 y 2009). En estos antiguos rituales, se legitimaban los liderazgos a través de ceremonias de bebida que incluían narrativas y cantos en los que los caciques relataban sus hazañas; también se efectuaban alianzas entre los grupos y se concertaban matrimonios, alentados por los cantos-danzas circulares (nmi) que solían practicar los más jóvenes. En relación con estas similitudes, analicé cómo las iglesias tobas se han constituido en un espacio que permitió dar continuidad a la organización y reproducción socio-cultural de estos grupos; por ejemplo, promoviendo la endogamia étnica o la construcción de nuevos liderazgos que entrelazan el poder religioso del pastor con el poder político que le otorgan las redes clientelares con los políticos criollos. No obstante, las iglesias también condujeron a la socialización en nuevos habitus, vinculados a: la ética pentecostal y a su prohibición de los "pecados" de fumar, beber alcohol y "bailar" en contextos no religiosos; las prácticas legales-burocráticas que organizan las iglesias, como la confección y uso de reglamentos escritos, actas, credenciales, permisos, registros contables; y las estéticas provenientes del folklore y la cultura popular de los criollos.

Las performances rituales del Evangelio incluyen discursos en toba y español que combinan breves lecturas de la Biblia, oraciones espontáneas, testimonios y relatos de los predicadores, y cantos con letras cristianas, ejecutados por hombres jóvenes con guitarras y bombos y, más recientemente, también con teclados electrónicos. Si bien se reproducen estructuras de la música folklórica y popular hegemónica en la región, y en los últimos años especialmente de la cumbia y reggeaton, en algunos géneros y estilos de canto pudimos constatar rasgos distintivos de las tradiciones musicales tobas (Citro y Cerletti, 2009). Un proceso similar se aprecia en las danzas. La danza del gozo, ejecutada preferentemente por los ancianos y adultos de manera individual, implica un paso semi-saltado similar al de los antiguos cantos-danzas así como gestos de curación que se asemejan a los de los chamanes. En el caso de La Rueda, una danza “a la carrera" que los jóvenes comenzaron a practicar a mediados de los '90, por su carácter circular y su vinculación con la formación de parejas, posee similitudes con el antiguo nmi de los jóvenes solteros, y por la 
vestimenta artesanal que utilizan los "dancistas", con los atuendos característicos de antiguos chamanes y caciques. En diversos trabajos (Citro, 2003 y 2009), he analizado los conflictos y tensiones que estas semejanzas con el pasado han generado entre los diferentes miembros de las iglesias; asimismo, examiné cómo, a través de estas transformaciones estéticas y de los conflictos ideológicos-culturales que conllevan, se redefinen posiciones identitarias en lo que refiere a la edad, el género y los liderazgos político-religiosos.

No obstante, más allá de estas tensiones y conflictos en torno a las legitimidades de ciertos géneros dancísticos y estilos de performance, durante mis trabajos de campo pude apreciar que la mayoría de los fieles coincidían en que tanto la música de los jóvenes como la danza evangélica de los adultos y ancianos eran las vías de acceso privilegiadas para alcanzar el ntonaGaq/gozo, el cual es descripto como un contacto con el Espíritu Santo en el cual la persona se "llena" de su "poder", generándose un estado emocional intenso que promueve la adquisición de "fortaleza" y "ánimo", el cese de dolores y, en general, la recuperación de la salud. Para los tobas, la dinámica de la salud-enfermedad se vincula con las relaciones intersubjetivas con el mundo humano y de los seres no humanos. Así, cuando algunos de estos vínculos se tornan conflictivos, afectan la propia corporalidad y producen la enfermedad; por ejemplo, cuando existen tensiones en las relaciones de parentesco, se infringen las prescripciones que rigen las relaciones con los seres poderosos, o se "peca" al desobedecer la ética pentecostal. Estas múltiples relaciones en la práctica se manifiestan en una dinámica de entradas y salidas, llenados y vacíos, del propio cuerpo: de aquellos elementos nocivos que producen las enfermedades y de los positivos que restablecen la salud. Es sobre esta interpretación que se ha producido una creativa articulación entre prácticas del chamanismo toba, el evangelismo y los tratamientos de la medicina occidental: tanto la succión del chamán como una intervención quirúrgica en el hospital "sacan" el mal del cuerpo, mientras que el soplo y la imposición de manos del chamán, el "gozo" evangélico y los "remedios" o "inyecciones" lo "llenan" de fortaleza y bienestar (Citro, 2009). 
En los discursos de los fieles, la posibilidad de "sentir" la presencia del Espíritu Santo y la "sanidad" a través del "gozo" son remarcadas como elementos fundamentales que los impulsaron a la conversión así como a la renovación de su creencia a través de la concurrencia semanal a los cultos. Además, este saludable "gozo evangélico" es interpretado como un reemplazo del pernicioso "gozo del mundo" prohibido por el pentecostalismo (provocado por el "alcohol, el cigarrillo, el juego de naipes y los bailes en las cantinas"), y el cual se cree condujo a los "antiguos tobas" (los no evangélicos) a la "pobreza" y a la desintegración de sus lazos familiares (Citro, 2009).

A continuación describiré las tres dimensiones de la experiencia intersubjetiva que, según mi hipótesis, son comunes a la eficacia ritual festiva, mostrando cómo, especialmente a través de la experiencia de gozo, el ritual del Evangelio opera su eficacia: legitima la creencia en el poder del Dios cristiano y en un nuevo código ético de conductas.

\section{El poder de la música para emocionar y movilizar nuestra corporalidad}

Luis, un joven guitarrista y cantante que participaba de los rituales del Evangelio, me explicó así su interpretación sobre el rol de la música:

La guitarra a través de mucho, de muchos sueños, visiones, es como verlo así, en los momentos de angustia, de tristeza, siempre es como escuchar a la guitarra sonar, es como una persona que te levanta ¿viste? y así de simple [...]. Yo no empiezo a guitarrear, uno, dos, tres días [...], es como dentro de mi siento una tristeza. Entonces pienso yo que es el primer camino que abre, es a través de la música, manifestar de esa forma, lo que vos ya sabés, de los cuatro [...]. No es como cantar así a lo natural, es como tener esa energía que los que están alrededor se empieza a... es como que alcanza eso, alcanza, SIENTEN ${ }^{3}$ esa POTENCIA, qué sé yo, empieza a lagrimear (por el gozo), o no sé cual es su reacción, lo que están escuchando, es como dejar brotar esto que ya ha nacido dentro mío [...], es como decirlo, como si fuera que tiene corrientes eléctricas, ¿viste?, [...] es como dejar SOLTAR esa energía, o sea todos los que están escuchando [...], le alcanza esa energía, si fuera que es como la energía misma de lo que es la natividad, entonces ya puede que se manifiesten [...] que sé yo, gritando, danzando [...]. es como SIENTE, en ese mismo instante, ya... 
En este relato, la fuerza de la música proviene de "la energía misma de la natividad", siendo ésta una expresión que designa la peculiar apropiación de Luis sobre las creencias tobas, especialmente a partir de su experiencia con cuatro espíritus compañeros (de ahí la mención de "los cuatro", los sueños y visiones); no obstante, después de esta experiencia similar a una iniciación chamánica, Luis optó por seguir "manifestando" esa "potencia" a través de su actividad como músico, solamente (Citro, 2001). En otros casos, también encontramos que la composición musical e incluso la misma decisión de los jóvenes de aprender a ejecutar un instrumento y participar como "cancionistas" en el Evangelio estaba mediada por sueños y visiones, aunque la entidad de los seres no humanos poderosos que allí intervenían variaba: entre figuras más cercanas a los antiguos dueños de las especies del monte y aquellas vinculadas al cristianismo.

Si bien estas interpretaciones evidencian las significaciones particulares que los tobas elaboran sobre el origen de la música, en sus explicaciones sobre los efectos sensoriales y emotivos, se aprecian experiencias que también son compartidas por otras tradiciones musicales y culturales. Para Luis, se trata de una "potencia" o "energía" comparable con la electricidad (la cual justamente acababa de llegar a su comunidad rural), que al ser "soltada", transforma no sólo al propio ejecutante, al que lo "levanta" de la angustia o la tristeza, sino que también "alcanza" a los performers, los cuales al "sentirla" pueden llorar, gritar, danzar y dejar atrás la tristeza. En este aspecto, sus reflexiones no resultaron tan diferentes de las que documenté, por ejemplo, en mi etnografía con los jóvenes porteños que asisten a recitales de rock; ellos y ellas también me hablaban de la "energía", "fuerza" o "potencia" de aquella música que, según sus dichos, no podían dejar de "sentir" en su cuerpo. De hecho, el término "sentir", con esta doble connotación física y emotiva, se convertía en hegemónico al momento de explicar por qué iban a un recital y "seguían" a su banda musical preferida "a todas partes" (Citro, 1997). Agregaría que mi propia socialización como performer en danza moderna y danzateatro estuvo dominada por discursos que destacaban este peculiar poder de la música para atravesar la corporeidad de los performers 
y generar diferentes movimientos corporales y estados emocionales.

Este especial poder de la música también puede rastrearse en algunas reflexiones filosóficas occidentales. Tal es el caso de Nietzsche (1997, p. 92), que sostenía que "la música [...] es también una excitación y una descarga globales de los afectos", aunque advertía que

para hacer posible la música como arte especial se ha inmovilizado a un gran número de sentidos, sobre todo el sentido muscular (al menos relativamente: pues en cierto grado todo ritmo continúa hablando a nuestros músculos): de modo que el hombre ya no imita y representa en seguida corporalmente todo lo que siente. Sin embargo, ése es propiamente [...] el estado dionisiaco primordial.

Es interesante agregar que incluso desde una perspectiva entroncada con la tradición racionalista, como es el enfoque estructural de Lévi-Strauss (1986, p. 36), se reconoce que la música es capaz de "sacudir" emociones e ideas, "fundirlas en una corrientes" y "sacar a relucir al individuo sus raíces fisiológicas".

En suma, lo que quiero destacar a través de estos diferentes relatos es su coincidencia en describir las profundas interconexiones entre sonoridades, corporalidades y emociones. Así, se suelen apreciar efectos performativos similares en lo que refiere a la capacidad de las músicas para inducir sensaciones y emociones entre los performers y sus audiencias; aunque, obviamente, cada música recurra a sonoridades particulares y promueva emociones y significaciones específicas.

Considero que la perspectiva semiótica de Turino, basada en la de Peirce, ofrece un fructífero marco explicativo para comprender este peculiar poder afectivo de la música. El autor señala que "los símbolos son signos sobre otras cosas, mientras que los íconos y los índices son signos de identidad [...] y conexiones directas" (Turino, 1999, p. 228, cursiva en el original). Por tanto,

el potencial afectivo de los signos es inversamente proporcional al grado de mediación, generalidad y abstracción..., los signos de nivel más bajo tienen más probabilidades de crear interpretantes emocionales y energéticos, mientras que los signos que involucran símbolos tienen más probabilidades de generar respuestas 
y razonamientos basados en el lenguaje (Turino, 1999, p. 234).

Muchos de los análisis musicales basados en modelos semióticos han enfatizado en su carácter icónico, sin embargo, para Turino ( 1999 , p. 227), la música y la danza también pueden operar como índices cuyo poder deriva de que "las relaciones signo-objeto están basadas en co-ocurrencias dentro de las propias experiencias de vida y, en consecuencia, resultan íntimamente ligadas como experiencia". Estas expresiones desarrollaron su propio potencial especial para producir respuestas emocionales e identificaciones sociales, debido a que "los índices continuamente incorporan nuevas capas de significado mientras que potencialmente también acarrean las primeras asociaciones - una suerte de bola de nieve semántica" (p. 235, cursiva en el original). En otras palabras, cada ejecución tendría la capacidad de reconectar al sujeto con una serie de afectos y significaciones que ese género provocó en performances anteriores.

Si bien esta capacidad podría extenderse a otros lenguajes estéticos, en las artes de la performance se hallaría intensificada, porque además de su capacidad metafórica, tradicionalmente asociada a lo icónico, estas artes también promoverían una indexicalidad emotiva más marcada. Es como si las músicas funcionaran metonímicamente, haciendo presente un mundo más amplio de sensaciones, emociones y significaciones con el que se fueron ligando a través de sus ejecuciones; lo peculiar es que no sólo las representan o evocan simbólicamente, sino que tienen un particular poder para hacerlas presentes, activarlas en los sujetos, re-vivirlas, como si la mediación entre el signo vehículo y las entidades señaladas se redujera o incluso anulara, para fundirse en una misma corriente existencial. Cabe recordar que las artes de la performance tienen la propiedad de desplegar el cuerpo vivo tanto en el espacio como en el tiempo, recogiendo ambas dimensiones de nuestra encarnación en el mundo y posibilitando la creación y vivencia de otras existencias posibles - y no sólo insinuándolas -, a través de la analogía con una imagen fija que "está-allí" pero no "deviene" en el tiempo. Como señaló Grotowski (1970, p. 18) para el teatro y podríamos extender a las artes de la performance en general, lo propio 
de ellas reside en la "comunicación perceptual, directa y viva entre actor y espectador". En suma, posiblemente en esta cualidad de ser artes encarnadas temporal y espacialmente también resida parte de su poder para provocar intensos experiencias y afectos en sus ejecutantes y audiencias.

Considero que esta cuestión de una indexicalidad emotiva más marcada que tiende a reducir o anular la mediación entre el signo y la entidad señalada podría encontrar un correlato explicativo en los hallazgos recientes de la neurofisiología de la percepción musical. Peretz (2009, p. 111), en una completa reseña sobre el tema, se pregunta si existiría "un circuito corto de la música a las emociones", en tanto "algunas características musicales serían rápida y efectivamente recogidas por una vía subcortical" que alimentarían el sistema cortical. Si bien el sistema límbico tiene un rol fundamental en las emociones, actualmente se postula que "éstas no se confinan allí sino que abarcan regiones corticales y subcorticales" (p. 106). No obstante, "la música puede acceder a estructuras subcorticales que están asociadas con refuerzos primarios", tal es el caso de regiones como "el núcleo accumbens", implicadas "en la respuesta a estímulos de intensa recompensa o motivacionalmente importantes", incluidos "chocolate" y "drogas de abuso"; así, la autora sostiene que la música puede ser tan efectiva como "la comida, la droga y las expresiones faciales", "en inducir respuestas afectivas mediadas subcorticalmente" (p. 107-108). De ahí esta hipótesis sobre el "circuito corto" de la música a las emociones que se plantea desde la neurofisiología, la cual nos permitiría complementar nuestra explicación semiótica y antropológica, sobre su "eficacia" para actuar como signos indexicales, directos y menos mediados, de emoción.

En la misma línea, es pertinente señalar que los estudios neuroquímicos vienen señalando cómo la experiencia de la percepción musical promueve la liberación de varios mediadores bioquímicos:

el neurotransmisor dopamina, el cual se cree que desempeñan un papel crucial en la respuesta a los estímulos de recompensa natural [...], está involucrados en el disfrute de la música [...], la dopamina es liberada 
[...] en sujetos que están escuchando una música agradable [...]. Además, se ha mostrado que los estímulos musicales promueven la liberación de endorfinas y los endocannabinoides en el torrente sanguíneo (Bosso et al., 2006, p. 189).

Finalmente, cuestiones referidas a la acción terapéutica benéfica asociada a la música, que encontramos tanto en el caso toba como en muchos otros rituales, también podrían vincularse al siguiente hallazgo:

La música también puede producir algunos efectos físicos al inducir la producción y liberación periférica de óxido nítrico (NO) [...]. Puesto que el NO es bien conocido por poseer una función antibacteriana, antiviral e inmunomoduladora, también es posible especular que escuchar música agradable podría ayudar a proteger al organismo contra infecciones bacteriales y virales, la activación inmune y endotelial excesiva, así como los efectos perjudiciales de la hipertensión arterial (Bosso et al., 2006, p. 189).

Hasta aquí hemos definido ciertos procesos que intervendrían en la percepción musical en general y que explicarían su resonancia en el cuerpo y su efectividad en la generación de emociones. Pasaremos ahora a analizar estos procesos en el caso de las prácticas corporales.

Una de las principales diferencias entre las prácticas corporales cotidianas y las utilizadas en situaciones de representación o performance reside en lo que Grotowski y Barba (apud Barba y Savarese, 1988) denominan "principio transcultural de amplificación". Este principio refiere al gasto de energía requerido para dar peso y proyectar la propia presencia en las técnicas públicas de representación, lo cual se opone a la economía o ahorro de energía de las técnicas corporales cotidianas. En estas últimas, cada persona tiende a utilizar el movimiento o la postura más cómoda, admitida en su contexto, para el fin que se propone. Indiscutiblemente, la medida del "derroche y del ahorro" varía en cada cultura, no obstante, los autores destacan que esta diferencia siempre estaría presente. Desde Laban (1958, p. 138), podría argumentarse que los movimientos expresivos que se diferen- 
cian de las acciones cotidianas implican un "cambio de énfasis" en alguno de los factores de movimiento - peso, espacio, tiempo, flujo y energía -, por eso, según este autor, la "sensación de movimiento" se transforma "en prominente en situaciones expresivas donde la experiencia psicosomática es de mayor importancia".

La ejecución reiterada de movimientos que implican un peculiar desgaste de energía o un cambio de énfasis en algunos de los factores de movimiento promueve cambios en la materialidad del cuerpo del danzante: suele alterar los ritmos respiratorios, circulatorios y las tonicidades musculares. En este sentido, autores como Wallon (1964) destacaron la profunda interrelación entre tonicidades musculares y emociones, las cuales van conformando una serie de patrones en los cuales los sujetos son socializados desde su nacimiento; y Alexander (apud Hemsy de Gainza, 1991, p. 165-167) señaló cómo estas tonicidades responden a las variaciones en el sistema vegetativo, las cuales justamente pueden ser inducidas por la percepción de ritmos diferenciales. Así, una vez más, estimulo musical, corporeidad y emociones evidencian sus profundas interrelaciones.

En suma, si cada lenguaje estético es, parafraseando a Armstrong, "una presencia afectante", "una presentación directa de la dimensión plenamente sensitiva de la experiencia" (apud Feld, 1994, p. 145), en la experiencia de corporizar la música, transformándola en nuevos gestos y movimientos que trascienden los de nuestra cotidianidad, esa dimensión sensitiva parecería intensificarse; máxime cuando nos situamos en un contexto ritual festivo, en donde las distancias entre actor y espectador se reducen o anulan y en donde la "inmersión" en la performance ya no es sólo a través de la percepción de los cuerpos de los otros sino del propio movimiento corporal, sea ejecutando un instrumento musical, cantando o danzando. Justamente, Bourdieu (1991, p. 125), en unas de sus definiciones sobre el cuerpo, señalaba que éste tiene la propiedad de "creer en lo que juega: llora cuando mima la tristeza. No representa lo que juega, no memoriza el pasado, actúa el pasado, anulado así en tanto que tal, lo revive". Así, esta peculiar capacidad del cuerpo de re-actualizar experiencias permitiría comprender esa indexicalidad emotiva más marcada que adscribimos antes a las músicas y ahora también a las danzas. 
En los rituales tobas, en los distintos géneros que componen la performance, se aprecia un marcado "desgaste de energía" que los diferencia de los actos cotidianos. El uso del cuerpo durante las prédicas y oraciones se caracteriza por la abundante gestualidad que acompaña el discurso, por la tensión muscular más marcada y por una mayor intensidad en las emisiones vocales y el abundante uso de entonaciones enfatizadoras, tal como sucedía en la narrativa de los antiguos caciques. En el canto y en las ejecuciones musicales también se aprecia una marcada intensidad en el volumen sonoro y en la tonicidad muscular. En lo que respecta a las danzas, implican un considerable desgaste de energía en saltos o corridas y se realizan durante varias horas, a pesar del calor típico de la región. Por ejemplo, la ejecución de un paso semi-saltado constante como el que realizan los adultos y ancianos suele provocar un efecto de incremento de la propia energía corporal, a través de la estimulación de los ritmos respiratorios y circulatorios, e incluso un aumento de la temperatura corporal. Alejandro Katache, explicándome sobre su danza, hizo la siguiente comparación: "es como la goma de la bicicleta, cuando infla" y seguidamente hizo una inspiración profunda y un gesto hacia afuera con sus brazos, como hinchando el pecho, y agregó: "se hace fuerte con la danza...".

En conclusión, el ritual involucra performances en las que el movimiento corporal y la voz son llevados a una intensidad notoriamente marcada respecto de la vida cotidiana, provocando cambios concretos en la materialidad de los cuerpos, sensaciones y emociones intensas, las cuales incluso a veces conducen a llantos y/o gemidos. Son justamente esas intensidades las que les indican a los tobas la presencia o el contacto con la fuerza y poder divino (l'añaGak), por eso, suele comentarse que, cuando "más cantos y más danzas" hay en un culto, "más gozo, más poder", y "más lindo se pone el culto". En contraposición, la falta de danzas genera apreciaciones negativas y se vincula con la "tristeza", el "aburrimiento", la "debilidad" y la presencia del "pecado" o la "enfermedad". Como nos decía una anciana dancista:

$\mathrm{R}$ : Danzo cuando hay alegría, por la alegría de mi corazón, a lo mejor más cerca de Dios [...], hay espiritu...

Silvia: ¿Y cómo siente el cuerpo? 
R: Más livianito, fuerte, cuando no hay gozo, más débil, ese cuerpo, enfermo...

Así los grados de intensidad de las sonoridades y el movimiento corporal operan no solo como íconos o metáforas simbólicas de la presencia/ausencia del gozo, sino que son también sus índices experienciales, conformados a lo largo de las sucesivas performances.

Para comprender cómo el ritual genera estos sentidos y alcanza su eficacia, es necesario analizar la segunda faceta planteada por nuestra hipótesis: cómo estas sensaciones y emociones, que la música y la danza por sí mismas generan, son re-intensificadas al superponerse y replicarse colectivamente en una peculiar fusión perceptiva y mímesis ritual.

\section{La intensificación colectiva: fusión perceptiva, mímesis y creencia ritual}

"Una vez reunidos los individuos, resulta del hecho mismo de su puesta en contacto, una especie de electricidad que los arrastra enseguida a un nivel extraordinario de exaltación. Cada sentimiento que se expresa repercute, sin encontrar resistencia, en todas las conciencias ampliamente receptivas a las impresiones externas: cada una de ellas hace eco a las otras y reciprocamente [...]. Surgen gestos violentos, gritos, verdaderos aullidos, ruidos ensordecedores de todo tipo, que todavía contribuyen a intensificar el estado que exteriorizan."

Durkheim (1995, p. 203).

El epígrafe nos recuerda los conocidos planteos de Durkheim acerca de los "estados de efervescencia ritual", inspirados en la naciente psicología de masas de inicios del siglo XX, que fueron retomados luego por las teorías funcionalistas antropológicas. Como puede apreciarse, para el autor, la "puesta en contacto" de los individuos y la amplia "receptividad" de las conciencias y los sentimientos expresados promovían esa "exaltación" colectiva. No obstante, al final de la frase, deja entrever que aquellos gestos y sonoridades, interpretados inicialmente como "exteriorización" de ese estado de "exaltación", también "contribuyen" a intensificarlo. Justamente, los desarrollos más recientes de los 
estudios de la performance, tal como se aprecia en los últimos trabajos de Turner (1992), Schechner (2000) o Tambiah (1984), permitieron destacar la capacidad de las expresiones estéticas para generar estados emocionales específicos y no sólo para "expresarlos"; de esta manera, se comenzaron a confrontar las concepciones dualistas tradicionales, en las que se tendía a segmentar un estado emocional, psicológico o socio-cultural, de su "expresión", "exteriorización" o "reproducción" a través de la corporalidad. Por eso, nuestra comprensión actual de estos estados emocionales característicos de los rituales festivos no puede limitarse a explicaciones basadas solamente en operaciones mentales de identificación y sugestión colectiva o en meras catarsis, pero tampoco, en aquellos planteos más reciente que, si bien reconocen las emociones como productos culturales, les adscriben un carácter fundamentalmente "discursivo", que sería luego "reproducido en los individuos en la forma de experiencia corporizada" (Feld, 1996, p. 97). Por el contrario, se trata de recuperar en nuestros análisis el rol de la intencionalidad y agencia corporal en la creación de la experiencia emocional, y para ello, consideramos de utilidad retomar la fenomenología existencial de Merleau-Ponty, pues su punto de partida es la experiencia vivida, perceptiva y motriz, del ser-en-el mundo.

Para este autor, toda percepción constituye un acto preobjetivo o pre-reflexivo en el que se evidencia una "comunión" entre el ser y el mundo percibido, y en el cual no existe aún la diferenciación entre sujeto y objeto, ni tampoco entre las diferentes sensaciones percibidas, pues nuestra percepción, en este estrato originario del sentir, es "sinestésica" (Merleau-Ponty, 1993, p. 228). Los fenómenos perceptivos y motrices implican una peculiar comprensión del mundo a través de la propia corporalidad, la cual "tiene su mundo o comprende su mundo sin tener que pasar por unas representaciones, sin subordinarse a una 'función simbólica' u objetivante" (Merleau-Ponty, 1993, p. 158). Nuestra relación práctica con el mundo no se da en términos de un "yo pienso", sino de un "yo puedo" (p. 154), a la manera de un "arco intencional" que nos "proyecta" hacia el mundo (p. 153). Así, la motricidad es nuestra "intencionalidad" originaria, pues mover el cuerpo “es apuntar a través del mismo, hacia las cosas, es dejarle que responda 
a la solicitación que éstas ejercen en él sin representación ninguna" (p. 156). Es sólo a partir del pensamiento reflexivo que nos escindimos como sujetos frente a un mundo y, por ejemplo, podemos distinguir las diferentes sensaciones y objetivar aquel mundo experiencial.

Desde esta perspectiva, podríamos sostener que la "comunión" o "conexión" perceptiva que se genera en una performance ritual en principio obedecería a este modus operandi, común a toda percepción cotidiana, sin embargo, lo que la diferencia es la peculiar intensidad del mundo que allí es percibido. Como vimos, esto se evidencia en la presencia afectante, sensorial y emotiva, de los lenguajes estéticos del ritual, pero también, agregaría, en la peculiar "redundancia" que éstos involucran, a partir de su replicación colectiva entre los performers y de su "fusión" o superposición (Tambiah, 1984). La replicación colectiva involucra los conocidos fenómenos de mímesis y empatía, tradicionalmente asociados al ritual. Taussig (1993, p. 25), en cierta consonancia con los planteos fenomenológicos, nos advierte que la mímesis, como facultad humana, no implica solamente una copia o imitación, "sino una conexión palpable, sensorial, entre el cuerpo del sujeto que percibe y lo percibido [...] una fusión del objeto de percepción con el cuerpo del que percibe y no sólo con el ojo de la mente"; asimismo, señala que el "poder mágico de la replicación" reside en que la "representación comparte o toma poder de lo representado" (p. 2). También Bourdieu (1991, p. 118) destacó la importancia de la capacidad mimética de los cuerpos en el ritual:

La eficacia ritual podría encontrar su origen en el poder sobre los otros que proporciona, y especialmente, sobre su cuerpo y su creencia, la capacidad colectivamente reconocida de actuar sobre los montajes verbomotores más profundamente ocultos, ya sea para neutralizarlos, ya para reactivarlos haciéndolos funcionar miméticamente.

Reconstruyendo entonces nuestra argumentación, encontramos que la percepción de las intensidades de una performance ritual sería capaz de impulsar al performer a fusionarse perceptivamente con estas intensas presencias afectantes y, en algunos casos, a replicarlas miméticamente, y esta conexión provocaría una potenciación de las sensaciones y emociones sentidas en el cuerpo propio, cargadas de 
una fuerte emotividad. En los rituales tobas del Evangelio, se aprecia cómo las ejecuciones instrumentales de los jóvenes, los cantos, oraciones y expresiones enfáticas, los gestos intensos y las danzas, tienden a superponerse y replicarse entre sí, con una intensidad creciente, y es en estos momentos, donde este potencial mimético y empático se hace más patente. Así, por ejemplo, los performers suelen señalar que la capacidad de la danza para generar el gozo no se restringe sólo al propio danzante, sino que también afecta a quienes la perciben: un dancista me explicaba "a través de mi danza, el que está debilitado puede sentir gozo"; o un joven músico, que "sin las danzas en la iglesia, cuando nosotros hacemos una reunión sin esto, a veces hasta nosotros no tenemos fuerza"; también un pastor decía que "si no hay danzas es pesado, llega el sueño, bajan las fuerzas [gesto con los brazos hacia abajo], con la música me viene el ánimo, cuando danzan los hermanos; cuando no hay danza, será que estoy solo, triste...". O un predicador también acotaba:

más usted ve en público, el público se levanta y grita y es más fuerte, más ánimo, ponele si yo estoy predicando, en el público, y se levanta, aplaude, yo tengo más ánimo, el ánimo de él contagia, entonces pone más ánimo, más fuerte, entonces usted no se da cuenta, bueno, ese es así, como que se contagia la fuerza, igual siempre he visto el músico, cuando la chica como se gozaba, saltaba, ahí empezó bailar ya, con toda la música.

La palabra toba nawoga, traducida como "contagio", suele utilizarse para caracterizar este poder mimético de la música y la danza en el ritual evangélico; asimismo, es la que describía las relaciones de contagio entre el cuerpo y el medio natural y social que lo rodea, especialmente en los tabúes de menstruación y embarazo y en otras prácticas rituales antiguas, como las escarificaciones de los cazadores o los paquetes de magia amorosa (Citro, 2009, p. 197-199 y p. 312315). Así, estos "contagios" develan una interesante continuidad en los modos en que operan la eficacia de estos diferentes rituales.

Es importante recalcar que este tipo de intensidades sensorio-emotivas y "contagios" sólo serán posibles cuando el fiel haya sido socializado en la performance ritual y, como sostiene Csordas (1993), en los "modos somáticos de atención" que éstos involucran, pues sin esa reiteración performativa, sin este habitus compartido, el ritual no 
podría alcanzar su eficacia. Así, por ejemplo, un nuevo participante del ritual del Evangelio, a través de la percepción sinestésica de los testimonios, músicas y danzas de los otros participantes, comienza identificando las sensaciones y emociones que estas provocan así como la "fortaleza" y "salud" que proveen, hasta que llegará un día, en que él o ella empezarán a "sentir algo", a emocionarse, y vivenciará el gozo. Justamente, la experiencia de iniciación en el gozo muchas veces opera como detonante de la conversión, y al relatarla, los participantes suelen enfatizar en el término "sentir": se siente la música, el ritmo o incluso la palabra bíblica que va activando una "imaginación corporizada" (Csordas, 1993) sobre el gozo, tal es el caso de las narrativas que lo describen como el "fuego" del Espíritu Santo y aluden al "calor" que este provoca. La mimesis del ritual es tal, que el "gozo" a menudo solo puede ser sentido en el transcurso de prácticas rituales en las que las horas acumuladas de danzas y cantos suelen generar sensaciones corporales de calor intenso. Como acertadamente sostuviera Bourdieu (1991, p. 154), “en tanto práctica performativa que se esfuerza por hacer ser lo que ella hace o dice, el rito, en más de un caso solo es, efectivamente, una mímesis práctica del proceso natural que se trata de facilitar".

Veamos un fragmento del relato de Noemí, una dancista adulta, quien al preguntarle si podía explicarme sobre el gozo, me contestó:

Noemí: Para mí es muy difícil explicar, porque por ejemplo nosotros tenemos fe, cuando oramos dentro de la iglesia y SENTIMOS, se SIENTE el gozo, a veces no nos dimos cuenta que estamos danzando, cuando nos dimos cuenta y ya estamos danzando...

Noemí, al igual que lo hicieron otros fieles, nos relata cómo "sin darse cuenta" comienza a danzar y sentir el gozo, evidenciando así que esta práctica no depende tanto de un acto de conciencia voluntario, sino más bien de una percepción sinéstesica, de un "sentir" global que la impulsa al movimiento con los otros. Se trata de una experiencia intersubjetiva e intercorporal (un "nosotros" que se siente "dentro de la iglesia") que implica una fusión perceptiva pre-objetiva así como una intencionalidad del performer, aunque es una intencionalidad, 
fundamentalmente, corporal ("difícil de explicar", "no nos dimos cuenta") y empática.

En suma, en este proceso de comenzar percibiendo a los otros performers, a sentir el gozo en el cuerpo propio y "creer", intervienen: la percepción sinestésica preobjetiva, las intensidades emocionales y el poder indexical de las músicas, la capacidad de las corporalidades actuantes para mimetizarse empáticamente con otras (e incluso re-actualizar y hacer presente experiencias pasadas) y la ideología religiosacultural. En efecto, es esta experiencia intersubjetiva de intensidades sensoriales y emotivas la que es significada o, para retomar los términos de Csordas (2008), "auto-objetivada", a través de categorías religiosasculturales específicas: en el Evangelio, como un contacto más cercano o comunión con lo divino, con el poder de Dios y el Espíritu Santo, que genera fortaleza y salud. Así, en este caso, es esta experiencia de intensidad extra-cotidiana la que le confiere su carácter de "alteridad", en tanto rasgo característico de toda experiencia religiosa, según ha sido propuesto por Csordas (2004). Retomando a Blacking (1990, p. 217), agregaría que estas experiencias vividas en la performance operan también cognitivamente, como "vías de conocimiento", pues se constituyen en un camino "experimental" para "conocer" y "probar" las creencias: los tobas se prueban a sí mismos la existencia del poder divino, pues pueden "sentirlo", percibirlo corporalmente en el ritual.

Para concluir, quisiera señalar que estas cuestiones vinculadas a los fenómenos de percepción, empatía y mimesis, en los últimos años, han recibido un renovado interés en las neurociencias. Especialmente a partir de los años '90, muchos de estos estudios se han dedicado a intentar demostrar la existencia en los humanos de lo que se conoce como "Mirror Neurons" o neuronas espejo: se trataría de conjuntos de neuronas que "incrementan su actividad durante la ejecución de ciertas acciones" y también "mientras se escucha o ve las acciones correspondientes siendo ejecutadas por otros" (Keysers, 2010, p. 971). Así, por ejemplo, cuando observamos una acción realizada por los demás,

nuestro sistema motor se activa como si nosotros estuviéramos ejecutando la misma acción [...]. De hecho, estas simulaciones motoras internas conducen a estados compartidos entre el sí mismo y los otros y pueden 
permitirnos comprender directamente el significado de las acciones de los otros sin una mediación reflexiva explícita (Avenanti y Aglioti, 2006, p. 24l, cursiva en el original).

Por otra parte, algunos estudios sugieren que las regiones cerebrales involucradas en la experiencia de emociones y sensaciones son también reactivadas mientras vemos esas emociones y sensaciones en los demás (Avenanti y Aglioti, 2006, p. 242; Keysers, 2010, p. 972).

En síntesis, los actuales modelos neurocientíficos sobre la empatía

postulan que un determinado estado motor, perceptivo o emocional de un individuo activa las correspondientes representaciones y procesos neuronales en otro individuo observando aquel estado [...]. Así, un mecanismo básico en la experiencia empática puede implicar la transformación de la información visual en tercera persona sobre los demás, en representaciones corporales en primera persona (Avenanti y Aglioti, 2006, p. 242).

Si bien estos hallazgos han sido objeto de gran entusiasmo por muchos neurocientíficos, algunos críticos más recientes señalan sus dudas acerca de las especulaciones de las que han sido objeto (Dinstein et al., 2008; Hickok, 2009). No obstante, se trata de un campo de investigación en pleno desarrollo, que permitiría comenzar a entender el correlato orgánico de los fenómenos de empatía y mimesis que, desde hace tanto tiempo, han llamado la atención de las ciencias humanas, y que en nuestro caso vemos operar en la eficacia ritual.

\section{Reiteración del placer y docilidad del poder ritual}

Pasemos ahora a analizar nuestro último punto: la relación entre placer, docilidad y poder. En músicas y danzas rituales ejecutadas sin imposiciones contra el propio deseo o voluntad, tal como acontece entre los tobas, la asociación con sensaciones y sentimientos vinculados al placer es característica. De hecho, como vimos, esto se aprecia en la propia definición del ntonaGak como experiencia placentera, de intensa alegría y gozo. Para comprender este placer o satisfacción que la experiencia del danzar suele generar, la perspectiva psicoanalítica 
ofrece algunas hipótesis, en especial en lo que atañe a las nociones de pulsión y sublimación. Si bien se trata de conceptos complejos que incluso plantean ambigüedades y transformaciones dentro de la teorías psicoanalíticas, en un trabajo anterior (Citro, 2009, p. 237), he argumentado que las danzas probablemente constituyan una de las prácticas estéticas en las que el proceso de "derivación" o "desviación" de lo pulsional, característico de la sublimación artística, tiende a ser menos marcado, en tanto el "objeto" de esa energía o "empuje" que parte "desde el cuerpo" en búsqueda de la satisfacción no deriva hacia otros canales expresivos no corporales, ni tampoco se dirige a un objeto o cuerpo exterior, sino que se despliega a través del movimiento en el cuerpo propio. Asimismo, he señalado que, en las definiciones freudianas, la satisfacción-placer no provendría solamente de la "supresión del estímulo" o "descarga total" de la tensión originadora de la pulsión, sino también de "experiencias de incremento placiente del estímulo y de asir esa diferencia entre un más y un menos de tensión", en tanto sensaciones que se inscriben en el cuerpo con un orden temporal, un ritmo específico (Citro, 2009, p. 237). Justamente, danzar, por la misma dinámica de todo movimiento corporal, implica la puesta en marcha de procesos de tensión-relajación tónica, generalmente acompañados de la dinámica de inspiración-exhalación, de resistirceder a la fuerza gravedad, que adquieren un ritmo y estructuración peculiar en cada tipo de danza, y estos procesos suelen asociarse con experiencias de un incremento placiente del estímulo. Como decían mis interlocutores tobas, refiriéndose al estilo in crescendo característico de sus performances: "más música, más danza, más gozo". Así, en el caso toba, el goce que proveen la danza y la música parecería ser uno de los fundamentos experienciales sobre el cual se erige el gozo en tanto significante evangélico. Por eso, así como la tristeza enferma el cuerpo, este peculiar goce corporal, significado como un contacto con el Espíritu Santo, sería capaz de curarlo.

Quisiera agregar que esta relación con lo pulsional también estaba presente, de diversas maneras, en las interpretaciones tobas. Por ejemplo, en el discurso evangélico pentecostal, si bien se diferencia el gozo de "la carne" y el del "espíritu", también se tiende a compararlos 
y a plantear ciertas similitudes. El relato de otro joven músico toba, Santiago, es elocuente:

Hay muchos que quieren gozarse tomando bebida alcohólica, pero ese gozo viene de la bebida, no viene de Dios. Por ejemplo, quieren olvidar las penas, la tristeza, la amargura y empieza a comprar un vinito, se emborracha. Pero en cambio los creyentes no se emborrachan con la bebida alcohólica, ellos se entregan a Dios completamente y ya están libres de su culpabilidad y empiezan a sentir ese gozo. [...] Los coritos parecen que son ingredientes que se agregan para mezclar esa libertad que siente la persona. Esos coros, cuando interpreta la música, la persona siente que hay un vacio que tiene que llenar y por medio de los músicos, más fuerza para seguir el Evangelio y cuando termina el culto se siente feliz y ya no siente esa tristeza, porque hay uno que reemplaza esa tristeza...

Como dice Santiago, el vacío y la tristeza son reemplazados por la música y la danza, por aquella sensación de "llenarse" con esa fuerza que, para él, proviene de Dios. Algunos intentarán llenarse con el alcohol o con el baile "del mundo", pero para los evangelios éstas son alegrías pasajeras que además conllevan desventajas, como las peleas que pueden ocasionar o los gastos que demandan. Estas últimas características son importantes de subrayar, pues si bien los creyentes insisten en el origen disímil del gozo de Dios y el del mundo, al hacerlo enfatizan en estas cuestiones más pragmáticas y no tanto en aquellos juicios de carácter moral sobre su supuesto carácter pecaminoso.

Finalmente, en relación con la comparación del gozo evangélico con el de la sexualidad, encontramos también algunas evidencias, aunque bastante invisibilizadas por el discurso evangélico. Un joven músico del evangelio, al que pude consultar sobre este tema, recordó la prédica de un anciano:

$Y$ dio una comparación del gozo del anciano [...] que tarda mucho en tener ese gozo, tiene sus coros predilectos [...]. Y bueno, comparó... de las edades, la de una jovencita de 15 años y de un viejo, que si se le colocara, o sea se le llevara a un lugar en la cama, se debían, eh... la, la calentura que tiene la jovencita y la del anciano y el resultado es que el anciano sí o sí va a tener resultado positivo de ese contacto que tiene con la jovencita, va a hacer despertar, despierta éso y eso es lo que más o menos, lo 
que más o menos se hace con los coros de la iglesia que debe tener jóvenes que están despiertos, bien, así con mucho ánimo. Bueno es asi más o menos el relato que él hizo, la comparación de eso, de la calentura de la jovencita y la del viejo, que da un buen resultado eso.

El gozo sexual y el gozo espiritual no aparecen aquí como mundos inconmensurables; por el contrario, la metáfora del encuentro sexual es la que permite mostrar la conjunción de las prácticas necesarias para que el ritual sea eficaz y, en este caso, para que los ancianos dancistas alcancen su gozo gracias al ánimo de los jóvenes, manifiesto en sus prácticas musicales.

Ya Turner (1980, p. 33) señalaba que los rituales, a través de sus símbolos, producían una yuxtaposición de "lo orgánico con lo social" que ponía las normas éticas y sociales en contacto con fuertes estímulos emocionales ligados a imágenes fisiológicas, y era esta yuxtaposición la que hacía que las normas, en tanto lo "obligatorio", se tornen "deseables". No obstante, más que el simbolismo fisiológico que involucra el estado de gozo, lo que nos ha interesado interesa indagar aquí es en los actos rituales, en las sensaciones y emociones que generan las performances musicales y corporales, y que hacen que lo "obligatorio", en este caso la creencia en el poder divino del Dios cristiano, con todas las normas éticas de conducta que implica, se hagan "deseables".

Bourdieu (1991, p. 118) advirtió que las utilizaciones de la danza y el canto en los rituales tendrían la función de "sugerir pensamientos y sentimientos" a través de "la ordenación rigurosa de las prácticas, la disposición regulada de los cuerpos, y en particular, de la expresión corporal del afecto". Así como Foucault caracterizó las "disciplinas" que crearon los "cuerpos dóciles" en los espacios institucionales del capitalismo, considero que también existiría otro tipo de docilidad basado, sobre todo, en esa "expresión corporal" y, agregaría, performativamente reiterada, de "los afectos" y emociones. A diferencia de aquella docilidad creada a partir de procedimientos rutinarios y desapasionados que se inscriben en los cuerpos, nos hallaríamos ante un procedimiento que, a través de la reiteración del placer y la emoción que dominan en un contexto ritual festivo, esto es, de las intensidades 
sensorio-emotivas, crea otros cuerpos dóciles, en este caso, a determinadas creencias. Bourdieu (1993, p. 120) expresó la importancia "del sufrimiento infligido al cuerpo" en la eficacia de los ritos de iniciación, tal vez esta relación no sólo se restrinja a los casos en que lo corporal genera intensidades sensoriales y emotivas asociada al dolor, quizás también se adhiera con más fuerza a otras creencias rituales cuando éstas impliquen ciertos estados de placer y satisfacción infligidos al cuerpo, cuando el goce de la danza y la música puede sentirse. En este sentido, cabe recordar que algunos de los últimos trabajos de Foucault, aunque abocados a otros campos de estudios, contribuyeron a destacar cómo las relaciones de poder también operan "induciendo placer", pues como sagazmente señala, si el poder "solo dijera no", si fuera esencialmente "represivo", nadie le obedecería (Foucault, 1979, p. 182).

En una completa reseña sobre los estudios del ritual, Kelly y Kaplan (1990, p. 140) señalan que autores como Combs y Shilling o Bourdieu enfatizan en "la imagen e inscripción corporal" como una de las formas por las cuales el ritual crea y sostiene la adhesión de sus partícipes, pero les critican que ello "no distingue al ritual de otras actividades", pues "el poder especial del acto ritual" residirá "en la falta de independencia asegurada para el participante ritual". Si bien coincido con la importancia de esta "falta de independencia" como elemento característico del ritual, lo cual en nuestra argumentación se corresponde con la fusión perceptiva y mímesis que éste promueve, considero que la inscripción o experiencia corporal que produce el ritual sí lo distingue de otras actividades, pues, como he argumentado, implica peculiares intensidades sensoriales y emotivas ( sean placenteras en los rituales festivos o dolorosas en los de iniciación), diferentes a las de la vida cotidiana, y es justamente a partir de la fuerza de estas experiencias que los sujetos se tornarían dóciles y quedan ligados, corporal, afectiva y reflexivamente, a la práctica ritual.

\section{Reflexiones finales}

Como corolario del análisis, cabe advertir que estas argumentaciones no deberían confundirse con una interpretación meramente sensorialista (desde la fenomenología y la psicología) y organicista 
(desde la biología); a lo que sí apuntan, en cambio, es a incorporar la experiencia vivida del cuerpo y lo que hoy sabemos sobre su funcionamiento orgánico, como parte explicativa de la eficacia ritual, enriqueciendo así las teorías socio-antropológicas que destacan sus aspectos simbólico-culturales e ideológicos así como las relaciones sociales y de poder involucradas.

Una reflexión antropológica sobre las performances que intente revalorizar el rol de las corporalidades, en sus aspectos sensoriales y motrices, no podría eludir el hecho de que aquello que denominamos cuerpo humano nos remite a la existencia de una cierta materialidad orgánica y a veces también de experiencia sensoriales y emotivas, en muchos casos compartidas. Como sostuve en un trabajo anterior (Citro, 2009, p. 39), este hecho, antes que dividirnos en ciencias aisladas y opuestas entre sí, podría constituirse en una "estimulante paradoja" que nos lleve a reflexionar sobre aquellos rasgos constitutivos que, a pesar de la reconocida diversidad cultural de los cuerpos y de sus variaciones según los sexos y edades, nos permiten seguir hablando de nuestros cuerpos, como un fundamento existencial compartido. En conclusión, pensamos que esta paradoja es insoslayable al momento de reflexionar sobre nuestra existencia encarnada, y es ésta la que nos ha impulsado a intentar estos diálogos interdisciplinares sobre la eficacia ritual en y desde los cuerpos.

\section{Notas:}

1 Dra. en Antropología, investigadora adjunta de CONICET, profesora Adjunta y coordinadora del equipo de investigación de Antropología del Cuerpo y la Performance, Instituto de Ciencias Antropológicas, Sección Etnología, Facultad de Filosofía y Letras, Universidad de Buenos Aires (www.antropologiadelcuerpo.com).

2 Dado el amplio espectro de manifestaciones que hoy abarca el concepto de ritual, me referiré aquí a los que implican una participación colectiva que promueve el acercamiento y la igualdad entre sus partícipes, tendiendo a reducir las distancias entre actores y espectadores; de ahí el uso de la adjetivación "festivos", retomando los trabajos clásicos de Bajtín (1994).

3 Los términos en mayúscula corresponden a aquellos que son enfatizados en el habla, a través de la intensidad y/o entonación vocal. 


\section{Referencias}

AVENANTI, Alessio; AGLIOTI, Salvatore. The Sensorimotor Side of Empathy for Pain. In: MANCIA, Mauro (Ed.). Psychoanalysis and Neuroscience. Milan: Springer-Verlag Italia, 2006. p. 235-256.

BAJTÍN, Mijail. La cultura popular en la Edad Media y en el Renacimiento: el contexto de Francois Rabelais. Buenos Aires: Alianza, 1994.

BARBA, Eugenio; SAVARESE, Nicola. Anatomía del actor. México: Gaceta/ International School of Theatre Anthropology, 1988.

BLACKING, John. Performance as a Way of Knowing: Practical Theory and the Theory of Practice in Venda Traditional Music-Making. In: XIV CONGRESSO DELLA SOCIETA INTERNAZIONALE DI MUSICOLOGIA, 1990, Torino. Atti... Torino: EDT, 1990. p. 1956-1966.

BOSSO, Marianna et al. Neurophysiology and Neurobiology of the Musical Experience. Functional Neurology, Roma: CIC Edizioni Internazionale, v. 21 , n. 4, p. 187-191, 2006.

BOURDIEU, Pierre. El sentido práctico. Madrid: Taurus, 1991. . Los ritos como actos de institución. In: PITT-RIVERS, Julián; PERISTIANY, John (Eds.). Honor y Gracia. Madrid: Alianza, 1993. p. 111 123.

CITRO, Silvia. Cuerpos festivo-rituales: un abordaje desde el rock. Tesis (Licenciatura) - Departamento de Ciencias Antropológicas, Universidad de Buenos Aires, Buenos Aires, 1997.

. Entre el "shamán, el gaucho, el astrólogo, el psicólogo..." y el bibliotecario: Retóricas del poder entre los qom. Relaciones, Buenos Aires: Sociedad Argentina de Antropología, v. XVI, p. 73-96, 2001.

. Cuerpos significantes: una etnografía dialéctica con los toba takshik. Tesis (Doctorado de Antropología) - Universidad de Buenos Aires, Buenos Aires, 2003.

. Cuerpos significantes: travesías de una etnografía dialéctica. Buenos

Aires: Biblos, 2009.

CITRO, Silvia; CERLETTI, Adriana. Aboriginal Dances were Always in Rings... Music and Dance as a Sign of Identity in the Argentine Chaco. Yearbook for Traditional Music, Canberra: International Council for Traditional Music, v. 41, p. 138-165, 2009.

CITRO, Silvia et al. Diálogos heterodoxos sobre el habitus: Bourdieu, Damasio y los nuevos desafíos para pensar el cuerpo. In: X CONGRESO ARGENTINO DE ANTROPOLOGÍA SOCIAL, 201 l, Buenos Aires. 
CORDEU, Edgardo. Aproximaciones al horizonte mítico de los Toba. Runa, Buenos Aires: Fac. de Filosofía y Letras de la UBA, v. 12, n. 1/2, p. 67-176, 1969.

CSORDAS, Thomas. Somatic Modes of Attention. Cultural Anthropology, American Anthropological Association: Wiley, v. 8, n. 2, p. 135-156, 1993. . Asymptote of the Ineffable. Current Anthropology, Chicago, The University of Chicago Press, v. 45, n. 2, p. 163-85, 2004. . Corpo, significado, cura. Porto Alegre: UFRGS, 2008.

DAMASIO, Antonio. El error de Descartes. Buenos Aires: Drakontos, 2008.

DINSTEIN, Ilan et al. A Mirror up to Nature. Current Biology, London/ Cambridge: Cell Press, v. 18, n. 1, p. 13-18, 2008.

DURKHEIM, Emile. Las formas elementales de la vida religiosa (1912). México: Diálogo Abierto, 1995.

FELD, Steven. Aesthetics as Iconicity of Style (Uptown Title); or, (Downtown Title) "Lift up-over Sounding": Geeting into the Kaluli Groove. In: KEIL, Charles; FELD, Steven (Eds.). Music Grooves. Chicago: The University of Chicago Press, 1994. p. 109-150.

. Waterfalls of Song: An Acoustemology of Place. In: FELD, Steven; BASSO, Keith (Eds.). Senses of Place. Santa Fe, NM: School of American Research Press, 1996. p. 91-136.

FOUCAULT, Michel. Microfísica del poder. Madrid: Ediciones de La Piqueta, 1979.

GROTOWSKI, Jerzey. Hacia un teatro pobre. México: Siglo XXI, 1970.

HEMSY DE GAINZA, Violeta. Conversaciones con Gerda Alexander. Buenos Aires: Paidós, 1991.

HICKOK, Gregory. Eight Problems for the Mirror Neuron Theory of Action Understanding in Monkeys and Humans. Journal of Cognitive Neurosciences, Cambridge: MIT Press/The Cognitive Neuroscience Institute, v. 21, n. 7, p. 1229-1243, 2009.

KELLY, John; KAPLAN, Martha. History, Structure and Ritual. Annual Review of Anthropology, Palo Alto: Annual Reviews, v. 19, p. 119-150, 1990.

KEYSERS, Christian. Mirror Neurons. Current Biology, London/Cambridge: Cell Press, v. 19, n. 21, p. 971-973, 2010.

LABAN, Rudolph. El dominio del movimiento. Buenos Aires: Fundamentos, 1958.

LÉVI-STRAUSS, Claude. Mitológicas: lo crudo y lo cocido I. México: FCE, 1986. 
MAUSS, Marcel. Las técnicas del cuerpo. In: Antropología. Madrid: Tecnos, 1979. p. 337-356. . Sociología $y$

MERLEAU-PONTY, Maurice. Fenomenología de la percepción. Barcelona: Planeta Agostini, 1993.

MILLER, Elmer. Armonía y disonancia en una sociedad: los Tobas argentinos. México: Siglo XXI, 1979.

NIETZSCHE, Friedrich. El nacimiento de la tragedia. Buenos Aires: Alianza, 1997.

PERETZ, Isabelle. Towards a Neurobiology of Musical Emotions. In: JUSLIN, Patrick; SLOBODA, John. Neuropsychology. Oxford: Oxford University Press, 2009. p. 99-126.

SCHECHNER, Richard. Performance: teoría y prácticas interculturales. Buenos Aires: Libros del Rojas/UBA, 2000.

SOUSA SANTOS, Boaventura de. Una epistemología del Sur. Buenos Aires: CLACSO, 2009.

TAMBIAH, Stanley. A Performative Approach to Ritual. In: . Culture, Thought and Social, Action. Cambridge: Harvard University Press, 1984. p. 123-166.

TAUSSIG, Michael. Mimesis and Alterity: A Particular History of the Senses. New York/London: Routledge, 1993.

TURNER, Victor. La selva de los símbolos. Madrid: Siglo XXI, 1980. . The Anthropology of Performance. New York: Paj, 1992.

TURINO, Thomas. Signs of Imagination, Identity, and Experience: A Peircian Semiotic Theory for Music. Ethnomusicology, Illinois: University of Illinois Press, v. 43, n. 2, p. 221-255, 1999.

WALLON, Henri. Del acto al pensamiento. Buenos Aires: Lautaro, 1964.

WRIGHT, Pablo. "Being-in-the-dream" Postcolonial Explorations in Toba Ontology. ph.D. Dissertation - Department of Anthropology, Temple University, 1997.

Recebido em 09/08/2012

Aceite em 15/09/2012 